\title{
Microstructures of Melt-Processed and Spark Plasma Sintered Ceramic Waste Forms
}

\author{
B.M. CLARK, P. TUMURUGOTI, S.K. SUNDARAM, J.W. AMOROSO, J.C. MARRA, \\ and K.S. BRINKMAN
}

\begin{abstract}
Hollandite-rich ceramic waste forms have been demonstrated to exhibit high durability while simultaneously accommodating a wide range of radionuclides in their matrices. This paper presents preliminary results on the preparation and characterization of ceramic waste forms prepared by two different methods - melt processing and spark plasma sintering (SPS). Both processes resulted in similar phase assemblages but exhibited different microstructures depending on processing method. The SPS samples exhibited fine-grained $(<1 \mu \mathrm{m})$ and dispersed phases, whereas the melt-processed sample contained larger grains $(10-20 \mu \mathrm{m})$ of specific phases. Additional data will need to be collected on the aqueous leaching durability and radiation resistance to evaluate each processing method for waste form performance.
\end{abstract}

DOI: $10.1007 / \mathrm{s} 40553-014-0035-4$

(c) ASM International (ASM) and The Minerals, Metals, \& Materials Society (TMS) 2014

\section{INTRODUCTION}

THE use of nuclear power to generate electricity necessitates methods to immobilize waste generated from those processes. There are many proposed waste form technologies for the storage of nuclear waste, including thermal and non-thermal processes. These consist of, but are not limited to, vitrification, ${ }^{[1]}$ hot isostatic pressing ${ }^{[2]}$ melt formation, ${ }^{[3]}$ spark plasma sintering (SPS), ${ }^{[2]}$ and cementation. ${ }^{[4]}$ Titanate-based ceramic waste forms specifically SYNROC ${ }^{[5-7]}$ and derivative materials have been widely studied for their potential to accommodate a large variety of radionuclides. The major phases targeted in SYNROC compositions are zirconolite $\left(\mathrm{CaZrTi}_{2} \mathrm{O}_{7}\right)$, hollandite $\left(\mathrm{Ba}_{x} \mathrm{Cs}_{y} \mathrm{Al}_{2 x+y} \mathrm{Ti}_{8-2 x-y} \mathrm{O}_{16}\right)$, and perovskite/pyrochlore $\left(\mathrm{CaTiO}_{3} / \mathrm{A}_{2} \mathrm{~B}_{2} \mathrm{O}_{7}\right.$, where $\mathrm{A}$ and $\mathrm{B}$ are different 3 or $4+$ cations). Zirconolite and perovskite/pyrochlore are targeted to immobilize the majority of actinides, while fission products (Cs and $\mathrm{Sr}$ ) are immobilized in hollandite phases. This work compares the microstructures and phase formation in SYNROC-type phases produced from melt processing and SPS methods.

\section{A. Structure}

As its name implies, zirconolite is targeted in the multiphase ceramic as the primary host for Zr. Zircon-

B.M. CLARK, Graduate Student, P. TUMURUGOTI, Graduate Student, and S.K. SUNDARAM, Inamori Professor of MSE, are with the Kazuo Inamori School of Engineering, The New York State College of Ceramics, Alfred University, Alfred, NY, 14802. Contact e-mail: sundaram@alfred.edu J.W. AMOROSO, Scientist, and J.C. MARRA, Senior Scientist, are with the Savannah River National Laboratory, Aiken, SC, 29808 K.S. BRINKMAN, Associate Professor, is with the Department of Materials Science and Engineering, Clemson University, Clemson, SC 29634.

Manuscript submitted February 1, 2014.

Article published online October 30, 2014 olite has a monoclinic structure and belongs to the $\mathrm{C} 2 / \mathrm{c}$ space group. There are five cation $(\mathrm{Ca}, \mathrm{Ti}$, and $\mathrm{Zr})$ sites, three of which are occupied by Ti. Two of the Ti sites are six-coordinated, and the third site is five-coordinated and has 50 pct occupancy. ${ }^{[8]}$ The zirconolite lattice is made up of alternating layers of Ti polyhedra and planes of $\mathrm{Ca}$ and $\mathrm{Zr}$ that lie parallel to (001) planes. The $\mathrm{Ca}$ and $\mathrm{Zr}$ atoms are aligned in alternating [110]-type rows with 8 - and 7-fold polyhedra, respectively. There is a rotation of $180 \mathrm{deg}$ around the c-axis between a pair of layers. ${ }^{[9]}$ Figure 1(a) displays the zirconolite crystal structure. Actinide and rare earth elements (REEs) can substitutionally enter the structure on $\mathrm{Ca}$ and $\mathrm{Zr}$ sites.

Pyrochlore is one of the ceramic phases of interest for the immobilization of nuclear waste due to its ability to incorporate actinides and REEs into its structure. Pyrochlore (Figure 1(b)) has the composition of $\mathrm{A}_{2} \mathrm{~B}_{2} \mathrm{X}_{6} \mathrm{X}^{\prime}$, where $\mathrm{A}$ is a 2 or $3+$ cation, $\mathrm{B}$ is a 4 or $5+$ cation, and $X$ and $X^{\prime}$ are anions $\left(\mathrm{O}^{2-}\right) \cdot{ }^{[10]}$ The structure of pyrochlore is related to a defect fluorite and can be envisioned as built-up layers of perovskite sheets. ${ }^{[1]}$ Perovskite materials have the general chemical formula of $\mathrm{ABX}_{3}$, where $\mathrm{A}$ and $\mathrm{B}$ are cations of different sizes and $\mathrm{X}$ is generally oxygen. The $\mathrm{B}$ atoms are generally smaller metal cations, such as $\mathrm{Ti}^{4+}$, whereas the A cations are larger metal cations such as $\mathrm{Ca}^{2+}$ or $\mathrm{Ba}^{2+} \cdot[12]$

The hollandite (Figure 1(c)) phase primarily incorporates $\mathrm{Cs}$ and $\mathrm{Ba}$ but can accommodate other alkali ions in its structure. The structure consists of tunnels running parallel to the crystallographic c-axis that are surrounded by walls of edge-sharing and corner-sharing octahedra. The symmetry of hollandite can be either tetragonal $(\mathrm{I} 4 / \mathrm{m})$ or monoclinic ( $\mathrm{I} 2 / \mathrm{m})$, depending on the trivalent cation $\left(\mathrm{M}^{3+}\right)$. The $\mathrm{M}^{3+}$ and $\mathrm{Ti}^{4+}$ ions are located in the octahedral sites, while the heavier elements like Cs and Ba occupy the tunnel sites. ${ }^{[13]}$ Since the ionic radii of these two ions are different, tunnel 


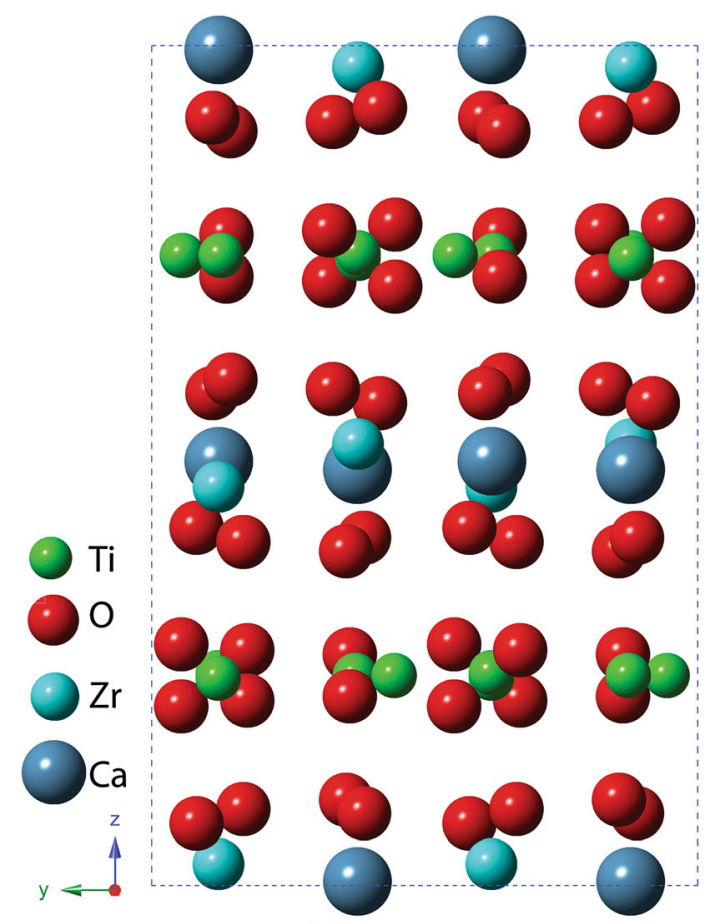

(a) $\mathrm{CaZrTi}_{2} \mathrm{O}_{7}$

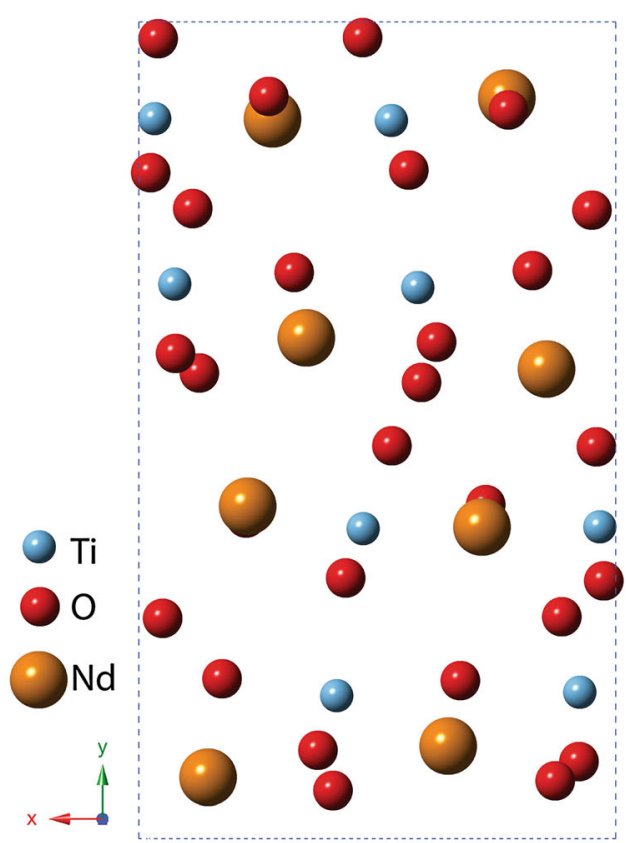

(b) $\mathrm{Nd}_{2} \mathrm{Ti}_{2} \mathrm{O}_{7}$

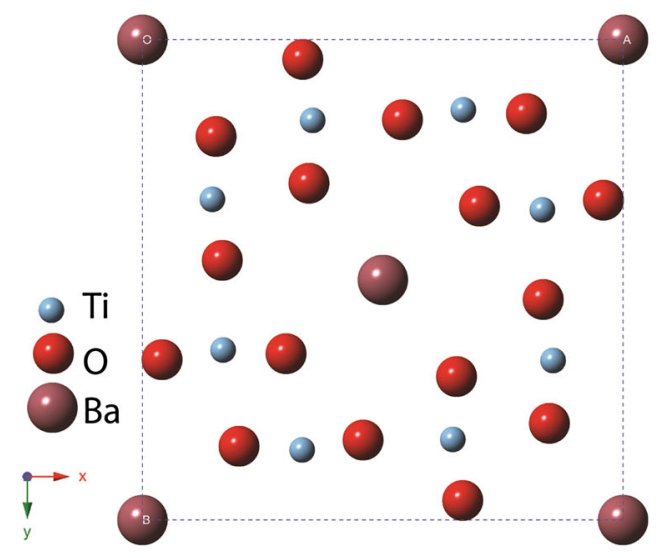

(c) $\mathrm{BaAl}_{2} \mathrm{Ti}_{6} \mathrm{O}_{16}$

Fig. 1-Structures of: (a) zirconolite $\left(\mathrm{CaZrTi}_{2} \mathrm{O}_{7}\right),(b)$ pyrochlore $\left(\mathrm{Nd}_{2} \mathrm{Ti}_{2} \mathrm{O}_{7}\right)$, and c) barium hollandite $\left(\mathrm{BaAl}_{2} \mathrm{Ti}_{6} \mathrm{O}_{16}\right)$.

distortions occur in the lattice, and hence the occupancy ratio $\mathrm{Ba}^{2+} / \mathrm{Cs}^{+}$in the tunnels is determined by the combination of $\mathrm{Ti}^{4+}$ and $\mathrm{M}^{3+}$ in the hollandite. In general, the waste stream composition is adjusted by adding dopants to make $\mathrm{M}^{3+}$ site of the lattice favorable for Cs incorporation. ${ }^{[14]}$

\section{B. Processing}

The method of processing a ceramic waste form affects the final properties such as aqueous durability and radiation resistance. This communication compares results from two processing methods; melt processing and SPS. In melt processing, combined carbonate and oxide precursors are heated to melting (above the liquidus temperature) followed by cooling to room temperature during which crystalline phases precipitate as the melt forms a solidified multiphase ceramic. Since melters are already being used for the vitrification of high-level waste (HLW) in many countries, melt processing allows for high throughput of waste forms with minimum airborne contamination. Extensive reported literature and knowledge in the area of melting and solidification of materials in general help prediction of phase assemblage and performance of the waste form. In addition, crystallization kinetics can be used to tailor a structure with maximum actinide concentration at the core and minimum at the rim, thus reducing the leachability. ${ }^{[15]}$ Disadvantages of melt formation are the potential volatilization of waste elements at the elevated temperatures needed for melting to occur and difficulty in controlling the cooling rate. 
SPS is of interest as an alternative formation technique because of the comparatively short processing time (a total of about 20 minutes) that is required to achieve a dense ceramic. The short processing times (along with self-contained sample inside the die) can reduce the volatilization of waste elements. Uniaxial pressure and a DC current are simultaneously applied to a graphite die containing the powder sample. The current generates resistive heating of the graphite die (and the sample if electrically conductive), which creates fast heating rates of up to $1000{ }^{\circ} \mathrm{C} / \mathrm{min} .{ }^{[16]}$ As shown in Figure 1, the current flows through the graphite punches, across and into the cylindrical die, and back to the punch located below the sample. This is the typical current flow during SPS experiments, assuming that the resistance of the sample is much greater than that of the graphite hardware. The SPS processing environment is inherently reducing, as it utilizes a graphite die, and is capable of producing high-density samples compared to melt processing. SPS is limited by the small throughput that can be obtained with current instrument configurations, and carbon diffusion from the die into the sample occurs at elevated temperatures. ${ }^{[16]}$

\section{EXPERIMENTAL}

Compositions of multiphase and single-phase hollandite waste forms based on simulated waste streams compositions generated from the advanced fuel cycle initiative (AFCI) aqueous separation process were developed by Savannah River National Laboratory (SRNL). Oxide and carbonate precursors were mixed together via ball milling with deionized water using zirconia media in a polyethylene jar for 2 hours. The slurry was dried overnight and then separated from the media. The blended powders were then subjected to melt or SPS processes.

One multiphase sample with metal oxide additions of $\mathrm{Cr}, \mathrm{Al}$, and $\mathrm{Fe}$ (designated CAF-MP) and one singlephase hollandite with metal oxide additions of $\mathrm{Cr}$ (designated Cr-SP) were subjected to melt processing and SPS. Melting was performed in a tube furnace by placing the loosely packed mixed powders into an alumina crucible and heating the furnace to $1773 \mathrm{~K}$ $\left(1500{ }^{\circ} \mathrm{C}\right.$ ) at a rate of $5 \mathrm{~K} / \mathrm{min}$, holding for 30 minutes, and allowing the furnace to cool to room temperature. The solidified contents were removed from the crucible and used for characterization.

Reaction via SPS was carried out using a FCT HP D 25 (FCT Systeme GmbH, Rauenstein, Germany) furnace with graphite dies and punches. A schematic of the die setup is shown in Figure 2. The unreacted powder was placed inside the graphite die with a thin layer of graphite paper between the die and the sample. The reaction schedule was as follows: a heating rate of $100 \mathrm{~K} / \mathrm{min}$ for both samples to a maximum temperature of $1273 \mathrm{~K}$ or $1313 \mathrm{~K}\left(1000{ }^{\circ} \mathrm{C}\right.$ or $\left.1040{ }^{\circ} \mathrm{C}\right)$, a hold time for 3 and 5 minutes for CAF-MP and Cr-SP, respectively, and a cooling rate of $100 \mathrm{~K} / \mathrm{min}$. The samples were subjected to $54 \mathrm{MPa}$ pressure throughout the reaction.

X-ray diffraction (XRD) was carried out using a D-2 Phaser (Bruker, Massachusetts) for phase identification. Powdered samples were made from the solidified melt samples and SPS disks for XRD. Density was measured using Archimedes principle. The microstructure of polished sections of the samples was observed using a FEI $^{\mathrm{TM}}$ Quanta $200 \mathrm{~F}$ scanning electron microscope (FEI, Hillsboro, Oregon). Energy-dispersive spectrometry (EDAX, Mahwah, New Jersey) was used to identify the different phases seen in SEM.

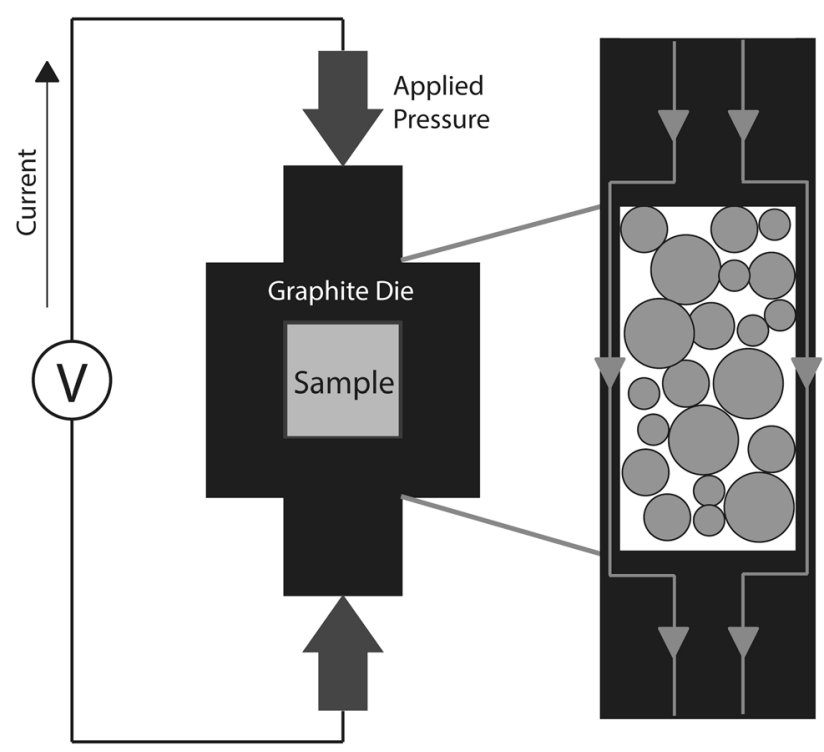

Fig. 2- Schematic of the graphite die setup in SPS.

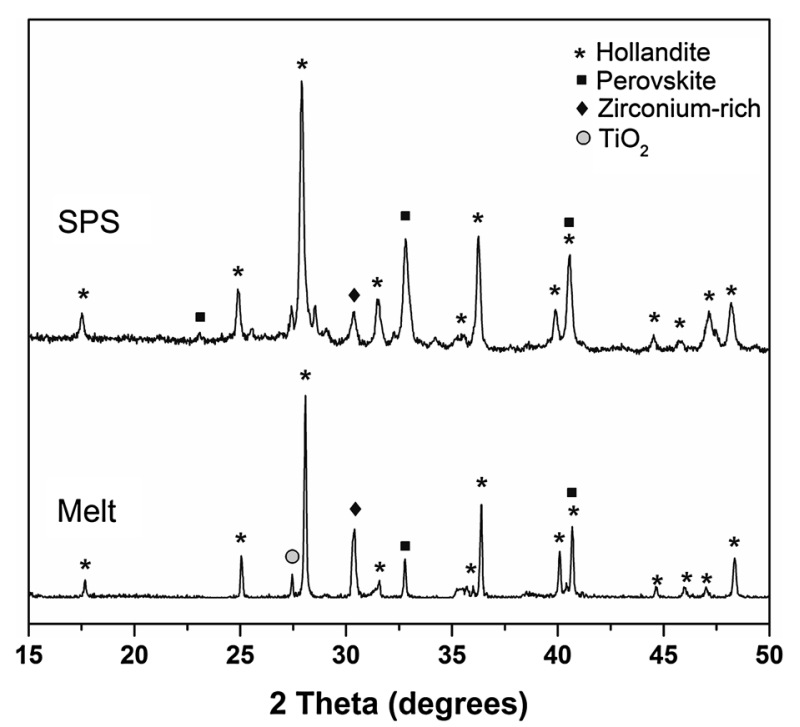

Fig. 3-XRD patterns of SPS and Melt-processed CAF-MP waste form samples. 


\section{RESULTS AND DISCUSSION}

\section{A. Multiphase Waste Forms}

The phases present after melt processing and SPS were similar. As inherent in any melt solidification, CAF-MP prepared by melt processing is observed to be porous or less dense $\left(4.30 \mathrm{~g} / \mathrm{cm}^{3}\right)$ than that of SPS sample $\left(4.64 \mathrm{~g} / \mathrm{cm}^{3}\right)$. Both contained major phases of hollandite and perovskite, and a small amount of an unknown zirconium-rich phase which will be discussed later in the microstructural analysis. Both samples contain unreacted $\mathrm{TiO}_{2}$, and the SPS sample contains minor amounts $(<5 \mathrm{pct})$ of additional unidentified phases. XRD patterns for the reacted materials are shown in Figure 3. In general, the peaks belonging to the SPS sample are broader than those belonging to the melt-processed sample, and this is attributed to crystallite size, as will be further discussed in the microstruc-

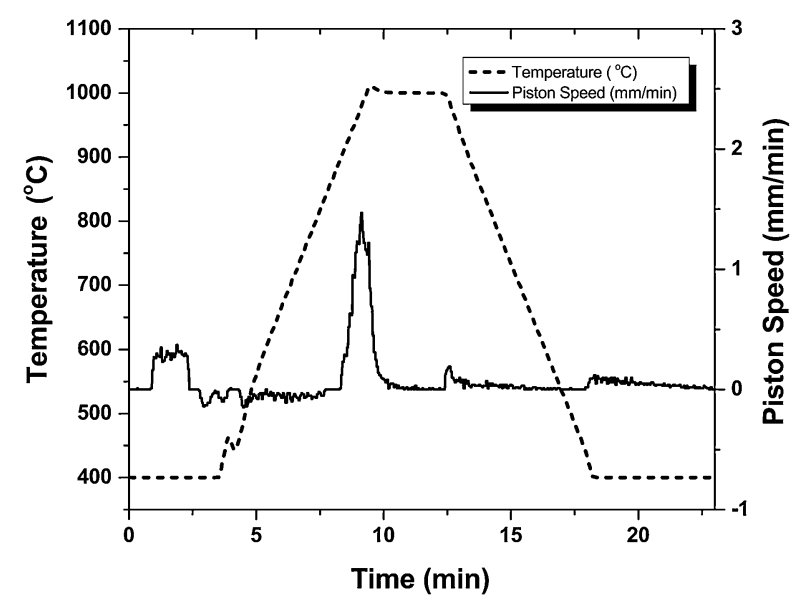

Fig. 4 - Reaction behavior of the CAF-MP sample during SPS. tural analyses. The SPS sample appeared to contain a greater amount of perovskite phase, relative to the major phase of hollandite, compared to the meltprocessed sample.

The reaction behavior during SPS is summarized in Figure 4 which shows a plot of the piston speed and temperature as a function of time. The peaks in the piston speed plot correspond to the pistons moving closer together (compaction). The peak that is present prior to the increase in temperature is due to the initial applied pressure. The large peak that occurs just before the maximum temperature at $1273 \mathrm{~K}\left(1000{ }^{\circ} \mathrm{C}\right)$ corresponds to the majority sample densification. The 3minute hold time allowed additional time for reactions to proceed toward completion. The small peaks that occur after the major peak are due to contraction upon cooling.

Contrary to the phase formation results, the microstructures of the samples using the two processes were dissimilar. Figure 5 compares the two microstructures. The sample processed by SPS shows a fine-grain structure with highly dispersed phases amongst the matrix (hollandite). In contrast, the melt-processed sample contains larger islands of the different phases that are aggregated to each other.

The phases seen in the microstructures were identified using a combination of EDS results and that seen in the XRD patterns. The appropriate phase fields are indicated in the images. Hollandite phase is represented with $\mathrm{H}$, perovskite with $\mathrm{P}$ and $\mathrm{P}$ ', a zirconium-rich phase with $\mathrm{Z}$, and $\mathrm{TiO}_{2}$ with $\mathrm{T}$. It should be noted that the identification of the zirconium-rich phase $(Z)$ is inconclusive from a combination of EDS and XRD analyses. This phase may also belong to zirconolite. Figures 6 and 7 compare the WDS maps of selected elements in these multiphase samples.

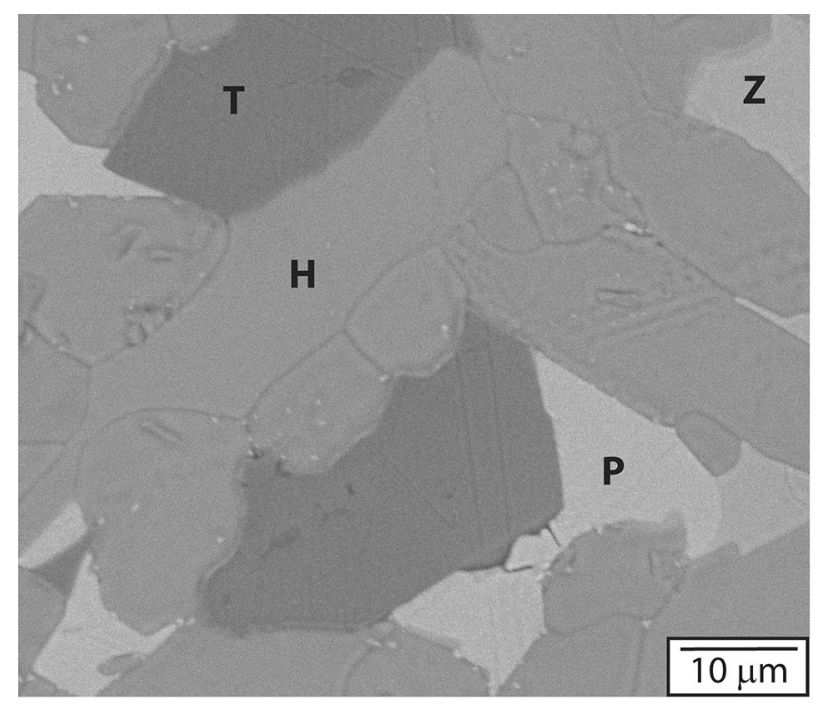

Melt

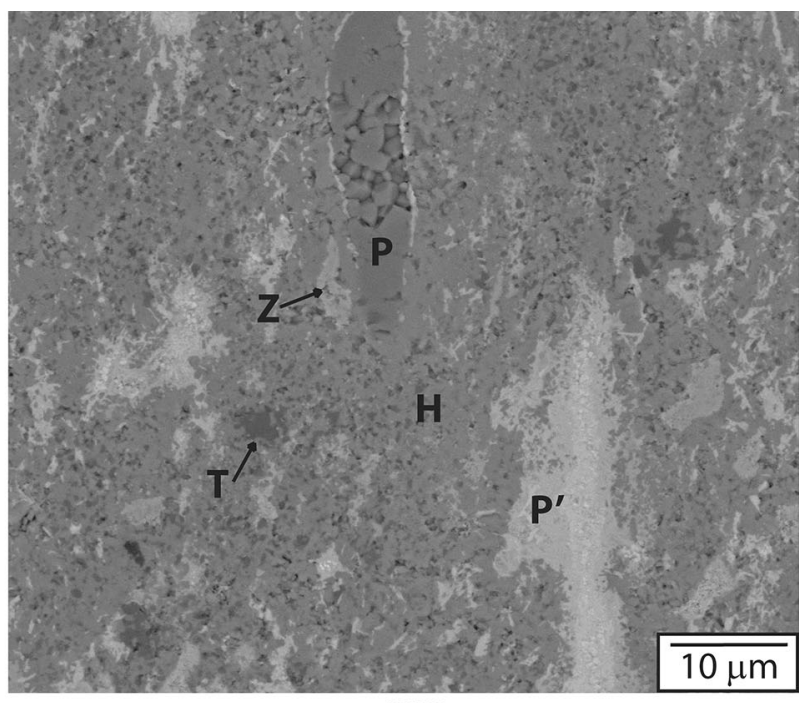

SPS

Fig. 5-Microstructures of SPS and melt-processed CAF-MP samples with indicated phase fields, $\mathrm{H}-$ hollandite, $\mathrm{P}$ and $\mathrm{P}^{\prime}-$ perovskite, $\mathrm{Z}$-zirconium-rich, and $\mathrm{T}-\mathrm{TiO}_{2}$. 

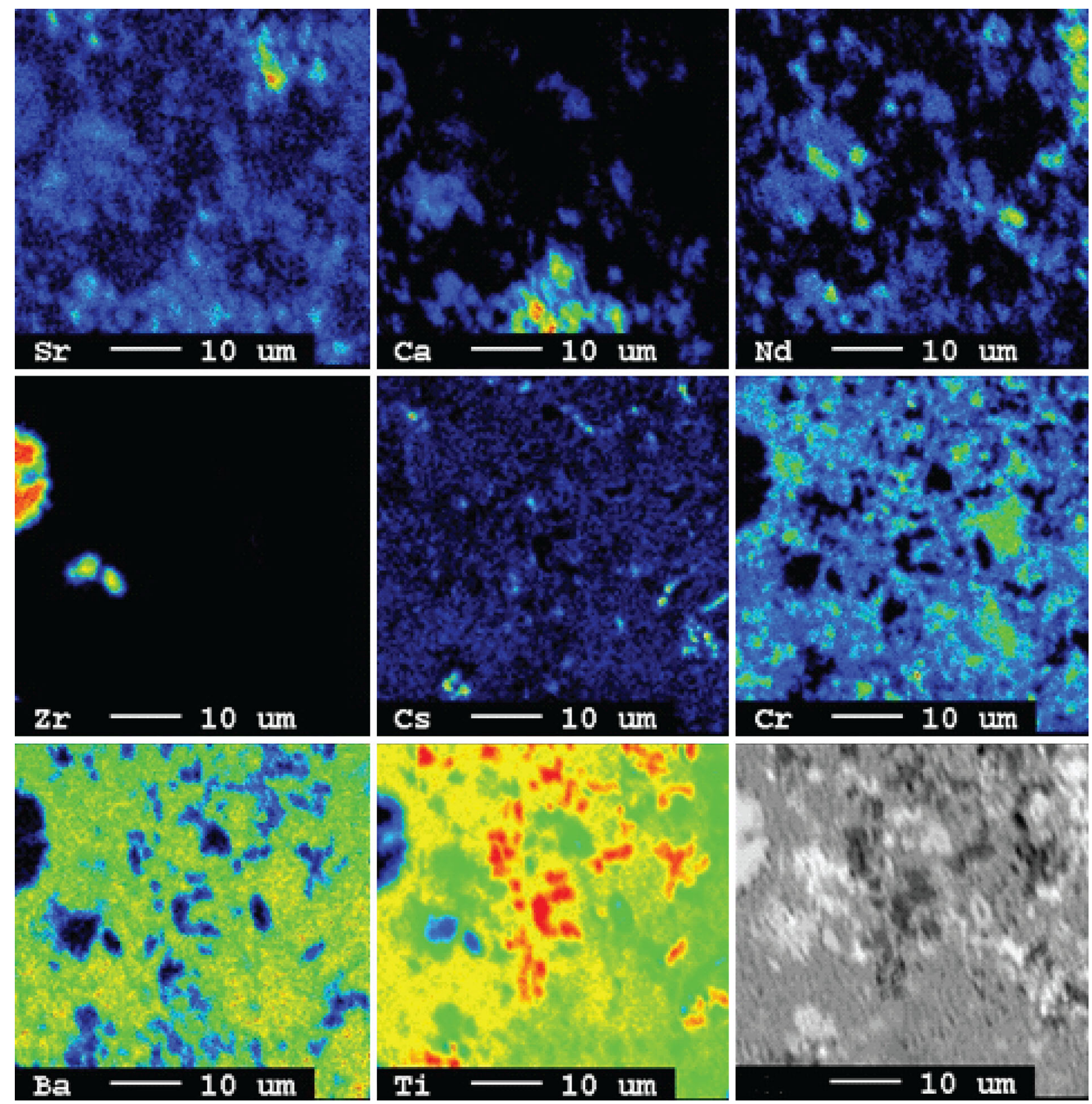

Fig. 6-Selected elemental maps by WDS in CAF-MP prepared by SPS.

In the SPS sample, hollandite formed the matrix of the sample and the remaining phases were dispersed throughout. The inter-dispersed phases ranged in size from $<1$ to $\sim 10 \mu \mathrm{m}$. EDS measurements revealed that two separate perovskite phases are present, a gray colored phase and a brighter phase, denoted by $\mathrm{P}$ and P', respectively, in Figure 5. The gray phase was rich in $\mathrm{Fe}$, while the bright phase was rich in REEs such as $\mathrm{Nd}$, in agreement with expected atomic mass ratios. A small amount of a cerium- and titanium-rich phase was seen in EDS, which may be the unidentified phase observed in the XRD pattern. The WDS results corroborate that hollandite makes up the matrix and that multiple perovskite phases are present, some high in alkaline earth elements ( $\mathrm{Sr}$ and $\mathrm{Ca}$ ) and other high in REE such as $\mathrm{Nd}$. The zirconium-rich phase consists mainly of $\mathrm{Zr}$ and very little $\mathrm{Sr}$ (of the elements that were observed in WDS), indicating that this phase may be a solid solution of $\mathrm{ZrO}_{2}$. It is important to note that Cs, one of the more volatile elements in waste streams, was detected in EDS and WDS measurements, confirming Cs retention by SPS. EDS collected at different points consisted of mixed signals from surrounding phases. Hence, finding the composition of a particular phase was challenging.

Initial visual observation of the melt-processed samples indicated that the samples were fully melted. Different phases were crystallized from the melt, with retention of some unreacted $\mathrm{TiO}_{2}$. Significant porosity 

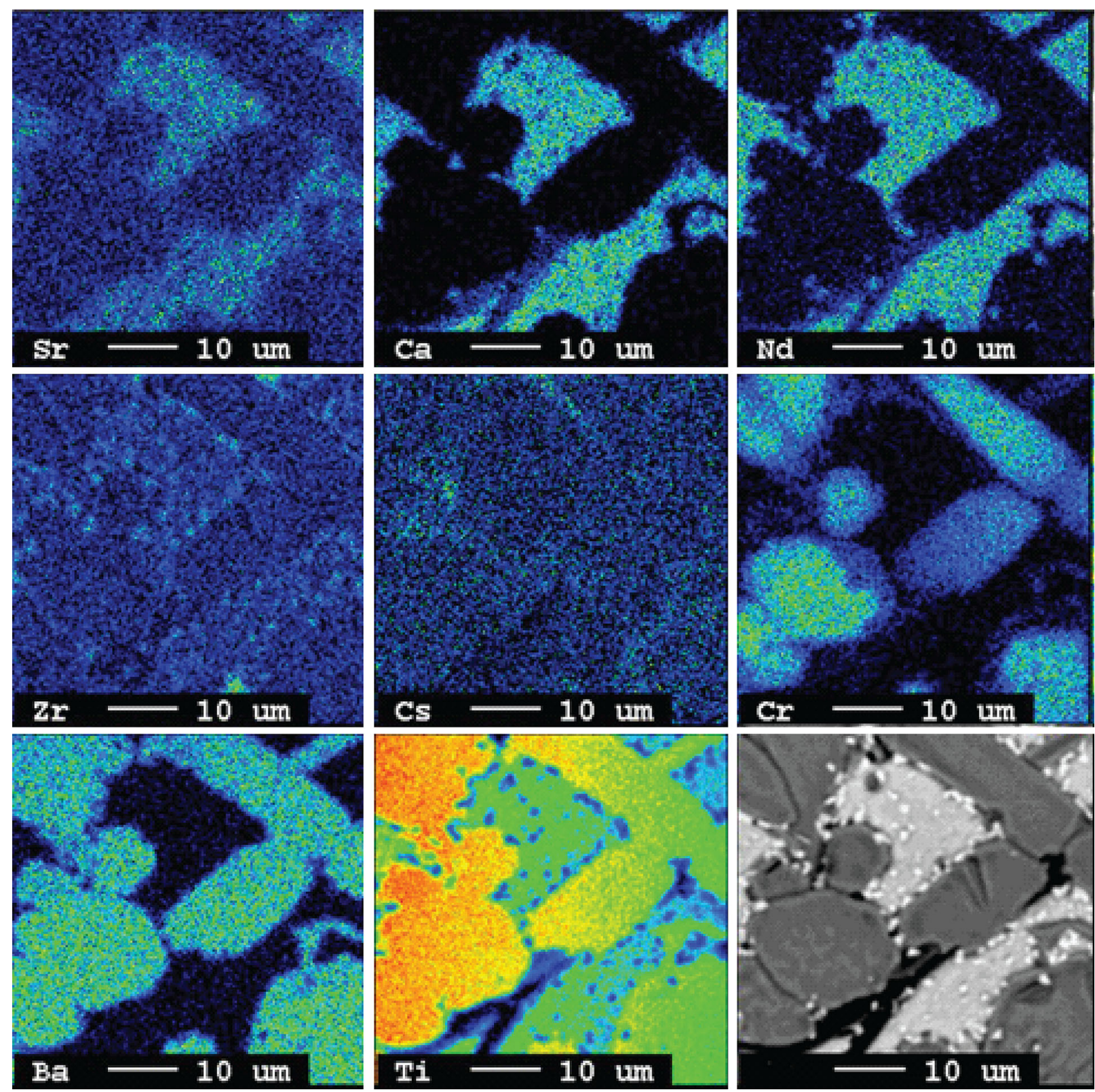

Fig. 7- Selected elemental maps by WDS in CAF-MP prepared by melt processing.

was observed in the microstructure. Cesium, one of the major elements in the multiphase mixtures $(\sim 3 \mathrm{wt}$ pct $)$, was not detected from EDS. Larger surface-area-tovolume ratio of small amount $(2 \mathrm{~g})$ of powders processed might have enhanced the volatilization of Cs. However, small amounts of Cs were detected in WDS mapping (Figure 7) that appeared to be segregated toward the grain boundaries of hollandite phase. From all the WDS maps in Figure 7, it could be observed that hollandite phase has elements predominantly $\mathrm{Ba}, \mathrm{Cr}, \mathrm{Ti}$, $\mathrm{O}$, and $\mathrm{Cs}$ as per the target composition. All other elements like $\mathrm{Ca}, \mathrm{Sr}, \mathrm{Nd}$, and $\mathrm{Ti}$ partitioned together into the bright perovskite phase (Figure 7), suggesting that different perovskite and pyrochlore phases could be formed in the process hosting different elements, actinides, REEs, etc. in their lattices.

\section{B. Single-Phase Waste Forms}

Both melt-processed and SPS produced the targeted hollandite phase. The SPS sample also contained a small amount of unreacted $\mathrm{Cr}_{2} \mathrm{O}_{3}$. The XRD patterns for the two samples are displayed in Figure 8.

The microstructures of the two Cr-SP samples are shown in Figure 9. The SPS sample displays a fine-grain structure. Islands of $\mathrm{Cr}_{2} \mathrm{O}_{3}$ can be seen dispersed throughout the microstructure. There is much porosity present in both samples. EDS confirmed the presence of Cs in the SPS sample. 
Melt processing of $\mathrm{Cr}-\mathrm{SP}$ was observed to have no bulk melting and resulted in a loosely bound material with large porosity. However, the reaction appeared complete and phase-pure hollandite was measured. Further, a green compact was used as the starting material during melting to get a dense body. Density of melt-processed Cr-SP is $4.01 \mathrm{~g} / \mathrm{cm}^{3}$ compared to that of $4.30 \mathrm{~g} / \mathrm{cm}^{3}$ for SPS sample. The microstructure of the polished surface resembles a sintered microstructure with a wide distribution of grain size, from $<3$ to $20 \mu \mathrm{m}$. It also confirms that minimal melting took place and surface diffusion occurred during the heating cycle.

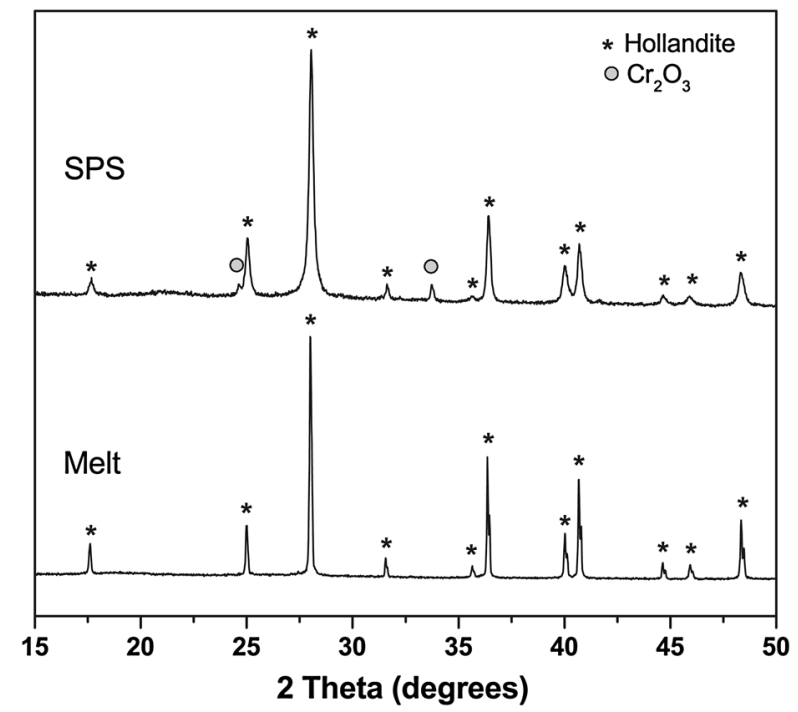

Fig. 8-XRD patterns of melt and SPS Cr-SP waste form samples.

\section{CONCLUSIONS}

Two processes were used to fabricate simulated multiphase waste forms, SPS and melting. The phase formation was similar in both processes, with two of the three targeted phases present, hollandite and perovskite. The microstructures of the SPS and melt-processed samples were very different. The SPS sample contained more fine-grained and dispersed phases, and the melted sample contained larger islands of specific phases. Two different perovskite phases were identified in the sample processed by SPS using EDS, with one of these phases containing a greater quantity of REE. The retention of cesium by melt formation is an issue and will need to be explored further. From the data presented in this communication, one process does not seem to be favored over another. Additional data will need to be collected on the aqueous leaching durability and radiation resistance to determine which process forms the superior waste form.

\section{ACKNOWLEDGMENTS}

The US Department of Energy (DOE)'s Nuclear Energy University Program (NEUP) supported this work. We are very grateful for the NEUP support, the advice by Dr. James C. Marra from SRNL, and the guidance by Dr. John D. Vienna from Pacific Northwest National Laboratory (PNNL). BMC acknowledges NEUP Graduate Fellowship. SKS acknowledges the Inamori Professorship supported by the Kyocera Corporation.

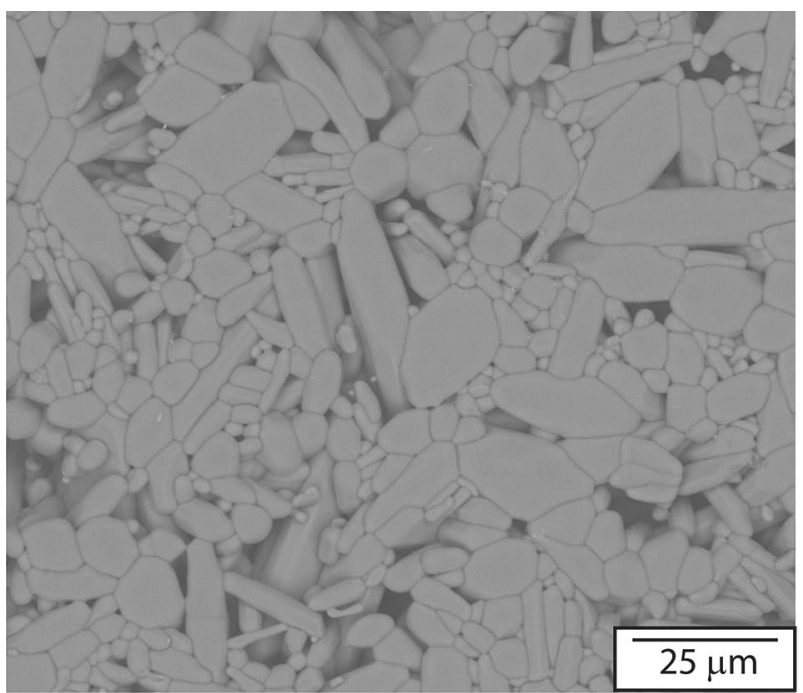

Melt

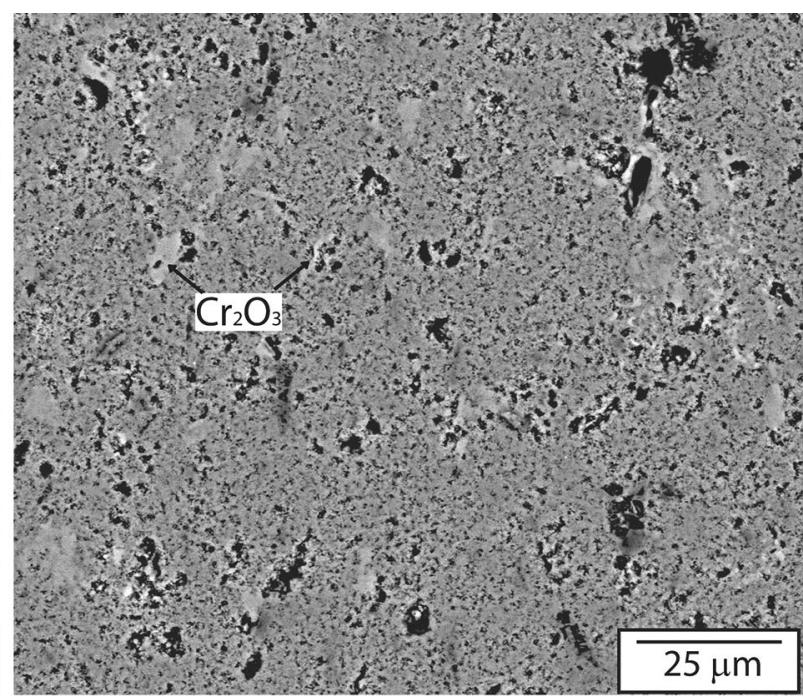

SPS

Fig. 9-Microstructures of melt and SPS Cr-SP waste form samples. $\mathrm{Cr}_{2} \mathrm{O}_{3}$ was found dispersed throughout the SPS sample. 


\section{REFERENCES}

1. E. Vernaz, S. Gin, and C. Veyer: Compr. Nucl. Mater., 2012, vol. 5, pp. 451-83.

2. M.L. Carter, M.W.A. Stewart, S.H.F. Leung, M. Colella, and E.R. Vance: Ceram. Trans., 1996, vol. 71, pp. 491-504.

3. J. Amoroso, J. Marra, S.D. Conradson, M. Tang, and K. Brinkman: J. Alloy Compd., 2014, vol. 584, pp. 590-99.

4. A.E. Osmanlioglu: Waste Manag., 2002, vol. 22, pp. 481-83.

5. A.E. Ringwood, S.E. Kesson, N.G. Ware, W. Hibberson, and A. Major: Nature, 1979, vol. 278, pp. 219-23.

6. T. Murakami: Nucl. Chem. Waste Manag., 1985, vol. 5, pp. 269 78

7. G.R. Lumpkin, K.L. Smith, and M.G. Blackford: J. Nucl. Mater., 1995, vol. 224, pp. 31-42.

8. H.J. Rossell: J. Solid State Chem., 1992, vol. 99, pp. 52-57.

9. A.A. Coelho, R.W. Chheary, and K.L. Smith: J. Solid State Chem., 1997, vol. 129, pp. 346-59.
10. K.B. Helean, S.V. Ushakov, C.E. Brown, A. Navrotsky, J. Lian, R.C. Ewing, J.M. Farmer, and L.A. Boatner: J. Solid State Chem., 2004, vol. 177, pp. 1858-66.

11. J. Sloan and R.J.D. Tilley: J. Solid State Chem., 1996, vol. 121, pp. 324-31.

12. A. Navrotsky: Chem. Mater., 1998, vol. 10, pp. 2787-93.

13. V. Aubin-Chevaldonnet, D. Caurant, A. Dannoux, D. Gourier, T. Charpentier, L. Mazerolles, and T. Advocat: J. Nucl. Mater., 2007, vol. 366, pp. 137-60.

14. W.J. Weber, A. Navrotsky, S. Stefenovsky, E.R. Vance, and E. Vernaz: MRS Bull., 2009, vol. 34, pp. 46-53.

15. S.V. Stefanovsky, A.G. Ptashkin, O.A. Knyazev, S.A. Dmitriev, S.V. Yudintsev, and B.S. Nikono: J. Alloy. Compd., 2007, vol. 444, pp. 438-42.

16. M. Nygren and Z. Shen: Ceramics Science and Technology, 1st ed., Vol. 3 Synthesis and Processing, p. 189, Wiley, KGaA, 2012. 